\title{
Analysis of Stock-Shareholder Associated Network Based on Complex Network
}

\author{
Haopeng Tong, Zhen Jia*, Min Zhang, Jinzhi Qi \\ College of Science, Guilin University of Technology, Guilin, China \\ Email: ‘jjjzzz0@163.com
}

How to cite this paper: Tong, H.P., Jia, Z., Zhang, M. and Qi, J.Z. (2021) Analysis of Stock-Shareholder Associated Network Based on Complex Network. Journal of Mathematical Finance, 11, 107-122. https://doi.org/10.4236/jmf.2021.111005

Received: January 6, 2021

Accepted: February 23, 2021

Published: February 26, 2021

Copyright (c) 2021 by author(s) and Scientific Research Publishing Inc. This work is licensed under the Creative Commons Attribution International License (CC BY 4.0).

http://creativecommons.org/licenses/by/4.0/ (c) (i) Open Access

\begin{abstract}
From the perspective of equity holdings, this article selects the stock and equity data related to the financial sector in the Shanghai and Shenzhen securities markets in China, uses the bipartite network model to construct stock-shareholders associated network and performs a single-mode projection on the network to obtain the stock correlation network, further study the structure and financial nature of the network. The study found that in the stock-shareholders associated networks, minority shareholders hold a large number of stocks, which on the one hand illustrates the investment direction of major shareholders, and has become a vein for retail shareholders to invest in stocks; on the other hand, it is confirmed that the long-term and large-scale holding of major shareholders can stabilize the financial market to a certain extent. The weight and degree distribution of the stock correlation network are non-uniform, and many of the state-owned banks have higher weight values, which reflects the close relationship between state-owned banks. Finally, the shareholder's holding behavior reflects that their identification with financial stocks in the A-share market tends to be consistent.
\end{abstract}

\section{Keywords}

Bipartite Network, Single-Mode Projection, Stock Correlation Network

\section{Introduction}

Since the 2008 financial crisis, people have begun to pay attention to the study of financial markets, and there are more and more research methods on financial markets. In recent years, a large number of scholars have used complex network methods to construct financial or stock networks, studying the relationship between various entities in the financial market and the spread of market risks. Yan Lin and Zhixin (2018) put forward a set of grade evaluation indicators of 
financial institutions in the financial network communication by studying the risk communication mechanism between financial institutions and combining with the financial network, so that the relevant regulatory agencies can supervise the financial institutions [1]. Yanfeng Sun and Chaoyong Wang (2018) defined a correlation coefficient based on textual mutual information, and compared with the traditional correlation coefficient method, they concluded that a network based on the correlation coefficient of textual mutual information can make the remaining nodes more connected and this method can effectively increase the importance of retaining nodes and dig out a better community structure [2]. Yu Wang and Xinrong Xiao et al. (2019) combed and summarized relevant international research from the perspective of financial network risk communication mechanisms. They found that the financial network diversifies the risk of a single financial institution, and at the same time, the financial network creates a contagion channel for risks among financial institutions, thereby increasing the conclusions of systemic financial risks [3]. Chuanmin Mi and Yuanyuan Qian (2019) used a complex network method to construct an Internet financial network, established an SEIS model with a latency period, and studied the inherent laws of Internet financial risk network propagation under both single and dual factors [4]. Runjie Xu (2020) used the risk factors between banks to construct a bank risk communication network and concluded that the main source of bank systemic risk is the external effects of microeconomic risk activities [5]. Ge You et al. (2020) used the complex network method to describe the research progress of financial market network and the evolution process of financial market network structure from the topological structure, evolution mechanism and risk contagion mechanism [6].

A bipartite network is a common network in life. It is a graph composed of two groups of nodes. The nodes in the group are not connected, and the nodes between the two groups can be connected. For example, the relationship between products and customers, the relationship between music works and audiences, the relationship between scientists and papers, etc., these relationships can be modeled and researched using a binary network. Shan Lu and Huiwen Wang (2019) studied the bank-asset dichotomy network and concluded that the collection of the same assets between different banks will lead to risk contagion, which in turn leads to large-scale bank bankruptcy [7]. Ke Gu and Ying Fan (2020) proposed a new algorithm to predict that the objects users do not like, which is more personalized than the previous algorithm [8].

Generally speaking, the typical stock correlation network modeling is based on the logarithmic return rate of stock daily trading, calculating the correlation coefficient between stocks, and then establishing the connection relationship between stocks according to the threshold method to build the correlation network model. This modeling method uses high-frequency data among stocks, which reflects the correlation of short-term stock return fluctuations. This article uses listed company equity and shareholder data, from the perspective of equity 
holdings, and uses a bipartite network model to establish a stock-shareholders associated network, reflecting the stable relationship between listed companies and shareholders over a long period of time. And further carry out single-mode projection on this bipartite network to obtain the stock correlation network, and analyze the network topology and financial statistics properties from the matrix weight, degree distribution, degree center and $K$-core.

The paper is structured as follows. Some preliminaries are introduced in Section 2. Section 3 studies the stock-shareholder associated Network. In Section 4, the stock correlation network is studied. Finally, Section 5 gives the conclusion of this paper.

\section{Preliminary}

\subsection{Definition of Graph}

A graph $G$ is an order triple $\left(V(G), E(G), \Psi_{G}\right)$ consisting of a nonempty vertex set $V(G)$, a set $E(G)$ of edges, and an incidence function $\Psi_{G}$ that associates with each edge an unordered pair of vertices of $G$. Let $G$ be a graph with the vertex set $V(G)=\left\{v_{1}, v_{2}, \cdots, v_{n}\right\}$ and the edge set $E(G)=\left\{e_{1}, e_{2}, \cdots, e_{m}\right\}$ [9]. The adjacency matrix of $G$ is the $n \times n$ matrix

$$
A=\left(\begin{array}{ccc}
a_{11} & \cdots & a_{1 n} \\
\vdots & \ddots & \vdots \\
a_{n 1} & \cdots & a_{n n}
\end{array}\right)
$$

where

$$
a_{i j}=\left\{\begin{array}{lc}
1, & \text { if } v_{i} \text { and } v_{j} \text { are adjacent } \\
0, & \text { otherwise }
\end{array}\right.
$$

\subsection{Bipartite Network and Single-Mode Projection}

A bipartite network is a special type of network. Its nodes are divided into two groups. There is no edge between the nodes in the group, and the nodes between the two groups can be connected, as shown in Figure 1.

Generally, a bipartite network can be expressed as, $G=(X, Y, E)$ where $X=\left\{x_{1}, x_{2}, \cdots, x_{n}\right\}$ and $Y=\left\{y_{1}, y_{2}, \cdots, y_{m}\right\}$ are the sets of two groups of nodes with different properties, and $E$ is the set of edges between nodes,

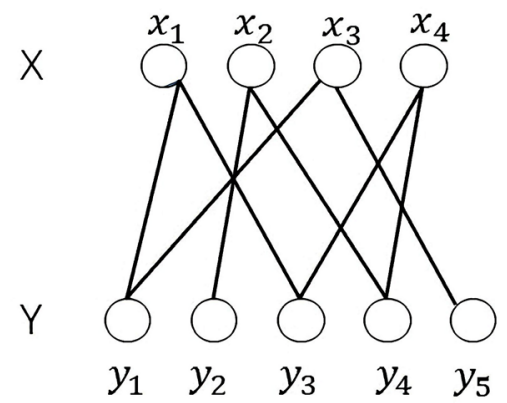

Figure 1. Schematic diagram of a bipartite network. 
$E=\left\{e_{i j} \mid x_{i}\right.$ and $y_{j}$ are connected, $\left.i=1, \cdots, n ; j=1, \cdots, m\right\}$. The adjacency matrix of network $G$ is recorded as $A=\left(a_{i j}\right)_{n \times m}$, where $a_{i j}=\left\{\begin{array}{ll}1, & e_{i j} \in E \\ 0, & e_{i j} \notin E\end{array}\right.$.

Since $X$ and $Y$ in the bipartite network are two sets of nodes with different properties, in general, matrix $A$ is asymmetric, which can reflect the topological structure of network $G$, and matrix $A$ represents network $G$, which is convenient for calculation and analysis of the topological properties of network $G$.

Single-mode projection is to project the bipartite network relationship onto one of the node sets, and project a two-dimensional bipartite network into a one-dimensional network to study. For example, the $X$-projection network refers to the projection of the bipartite network $G$ onto the node set. The specific projection method is: if in the bipartite network, nodes $x_{i}$ and $x_{j}$ are connected to the node $y_{k}$ at the same time, then in the $X$-projection network, the nodes $x_{i}$ and $x_{j}$ have connected edges, as shown in Figure 2. Similarly, $Y$-projection network can be defined

Take the bipartite network shown in Figure 2(a) as an example, its adjacency matrix is:

$$
A=\left[\begin{array}{llll}
1 & 1 & 0 & 1 \\
0 & 1 & 1 & 0 \\
1 & 0 & 1 & 1
\end{array}\right]
$$

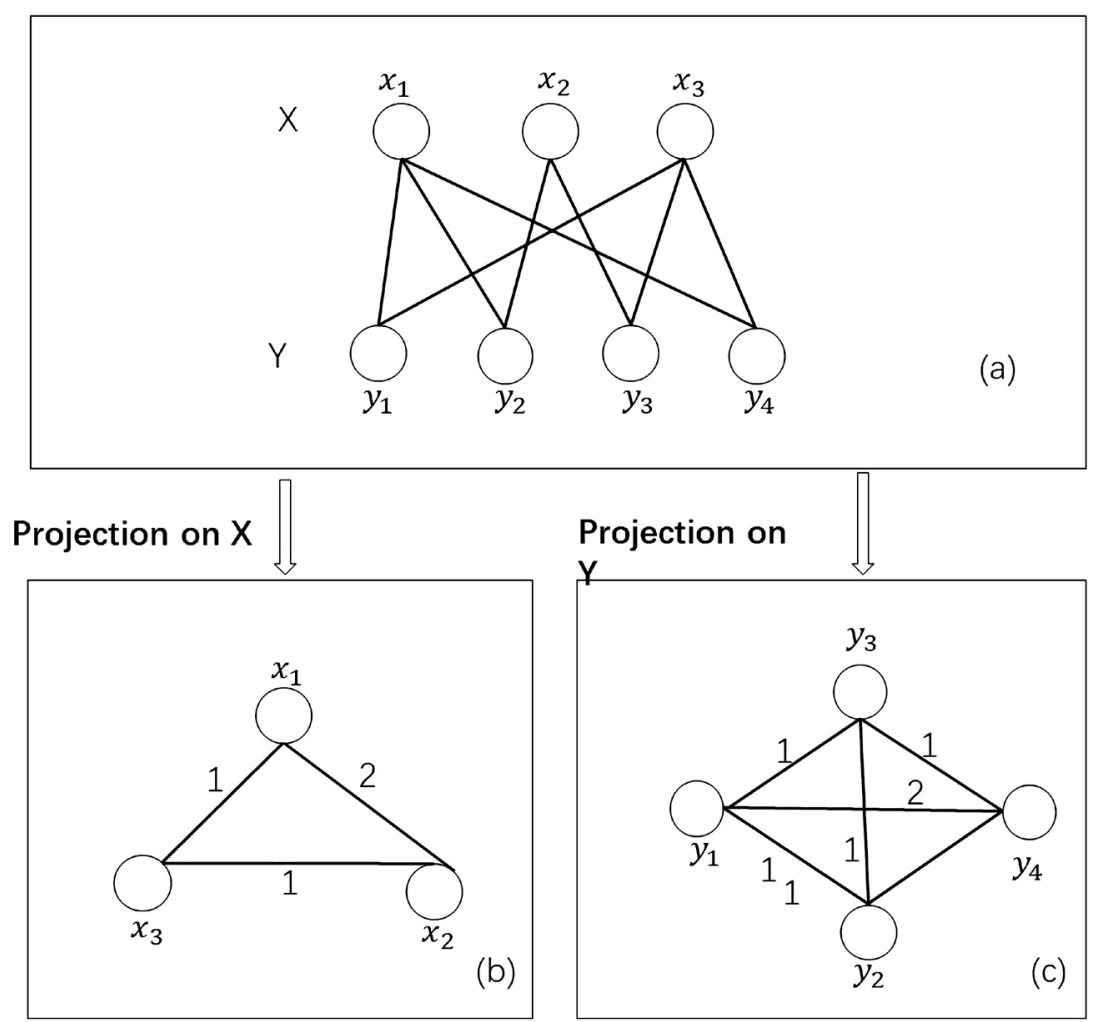

Figure 2. Projection diagram of a bipartite network (a) Bipartite network; (b) $X$-projection network; (c) $Y$-projection network. 
Thus, the $X$-projection network and $Y$-projection network are obtained, and the adjacency matrices $W_{X}$ and $W_{Y}$ are respectively:

$$
W_{X}=\left[\begin{array}{lll}
0 & 1 & 2 \\
1 & 0 & 1 \\
2 & 1 & 0
\end{array}\right], W_{Y}=\left[\begin{array}{llll}
0 & 1 & 1 & 2 \\
1 & 0 & 1 & 1 \\
1 & 1 & 0 & 1 \\
2 & 1 & 1 & 0
\end{array}\right]
$$

To generalize the above process, write the adjacency matrix of the $X$-projection network as $w_{X}=\left(w_{i j}\right)_{n \times n}$, then where $w_{i j}=\sum_{k=1}^{m} a_{i k} \cdot a_{j k}, i, j=1, \cdots, n$, and similarly write the adjacency matrix of the $Y$-projection network as $W_{Y}=\left(w_{i j}\right)_{m \times m}$, then there is $w_{i j}=\sum_{k=1}^{n} a_{k i} \cdot a_{k j}, i, j=1, \cdots, m$.

In fact, the adjacency matrices $W_{X}$ and $W_{Y}$ of the $X$-projection network and $Y$-projection network are both symmetric weight matrices. In the $X$-projection network in Figure 2, the element of matrix $W_{X}$ is because $x_{1}$ and $x_{3}$ have two neighbor nodes $y_{1}$ and $y_{4}$ in common, so the weight between $x_{1}$ and $x_{3}$ is 2 . The weight between two nodes is equal to the number of common neighbor nodes between the two nodes. The greater the weight between nodes, the closer the connection between them. If the two sets of nodes $X$ and $Y$ are regarded as a collection of customers and commodities, this close connection means that two customers' preferences for items in the customer-related network have a high similarity; If the two sets of nodes $X$ and $Y$ are regarded as a collection of stocks and shareholders, the larger $w_{i j}$ means that the two stocks $x_{i}$ and $x_{j}$ are favored and recognized by more of the same institutions. Therefore, the bipartite network can better analyze the relationship between nodes in the group after single-mode projection.

\section{Stock-Shareholder Associated Network Modeling and Analysis}

\subsection{Data Source}

This article mainly studies the stocks of related industries in the financial field, that is the stocks issued by listed companies such as banks, insurance, and securities. Obtain the public data information of listed companies in the financial sector from China's Shanghai Stock Exchange and Shenzhen Stock Exchange, and obtain the top ten shareholders of stocks. This article selected 78 financial stocks (including 29 bank stocks, 6 insurance stocks and 43 securities stocks) and 68 of the top ten shareholders of these stocks (hereinafter referred to as shareholders). Due to the limitation of the number of shares, we excluded individual shareholders and shareholders who only hold one stock in the study.

\subsection{Stock-Shareholder Associated Network Modeling}

Divide the data into two categories. The first category is a collection of 78 finan- 
cial stocks, denoted as node set $X=\left\{x_{1}, x_{2}, \cdots, x_{i}, \cdots, x_{78}\right\}$, and the second category is a collection of the top ten shareholders/institutions (excluding individual shareholders) whose shareholders are the above financial stocks. It is node set $Y=\left\{y_{1}, y_{2}, \cdots, y_{j}, \cdots, y_{68}\right\}$. Rows represent nodes of the first type, and columns represent nodes of the second type. If the institution $y_{j}$ in the second type set is a shareholder of the first type of stock $x_{i}$, the corresponding element is $a_{i j}=1$, otherwise $a_{i j}=0$. This results in the adjacency matrix $A_{78 \times 69}$ of the stock-shareholder associated network, which reflects the topological structure of the bipartite network.

\subsection{Analysis of Stock-Shareholder Associate Network}

It can be seen from Figure 3 that the minority shareholders hold a large number of shares in the stock-shareholder associated network, reflecting the non-uniform holdings of these shareholders. And the following is a further analysis of the shareholders in the stock-shareholder associated network.

Assuming that shareholder $y_{j}$ 's shareholding (the number of shares $y_{j}$ held by $x_{i}$ ) is $h_{j}$, the expression of $h_{j}$ is as follows:

$$
h_{j}=\sum_{i=1}^{n} a_{i j} .
$$

According to this definition, the shareholding $h_{j}$ of each shareholder in the stock-shareholder associated network can be calculated and presented in a table. As shown in Table 1, the top shareholders with shareholding $h_{j}$ are shown.

It can be seen from Table 1 that the top four institutions with the highest shareholder holdings are Hong Kong Securities Clearing Company, China Securities Finance Corporation Limited, Central Huijin Asset Management Co.,

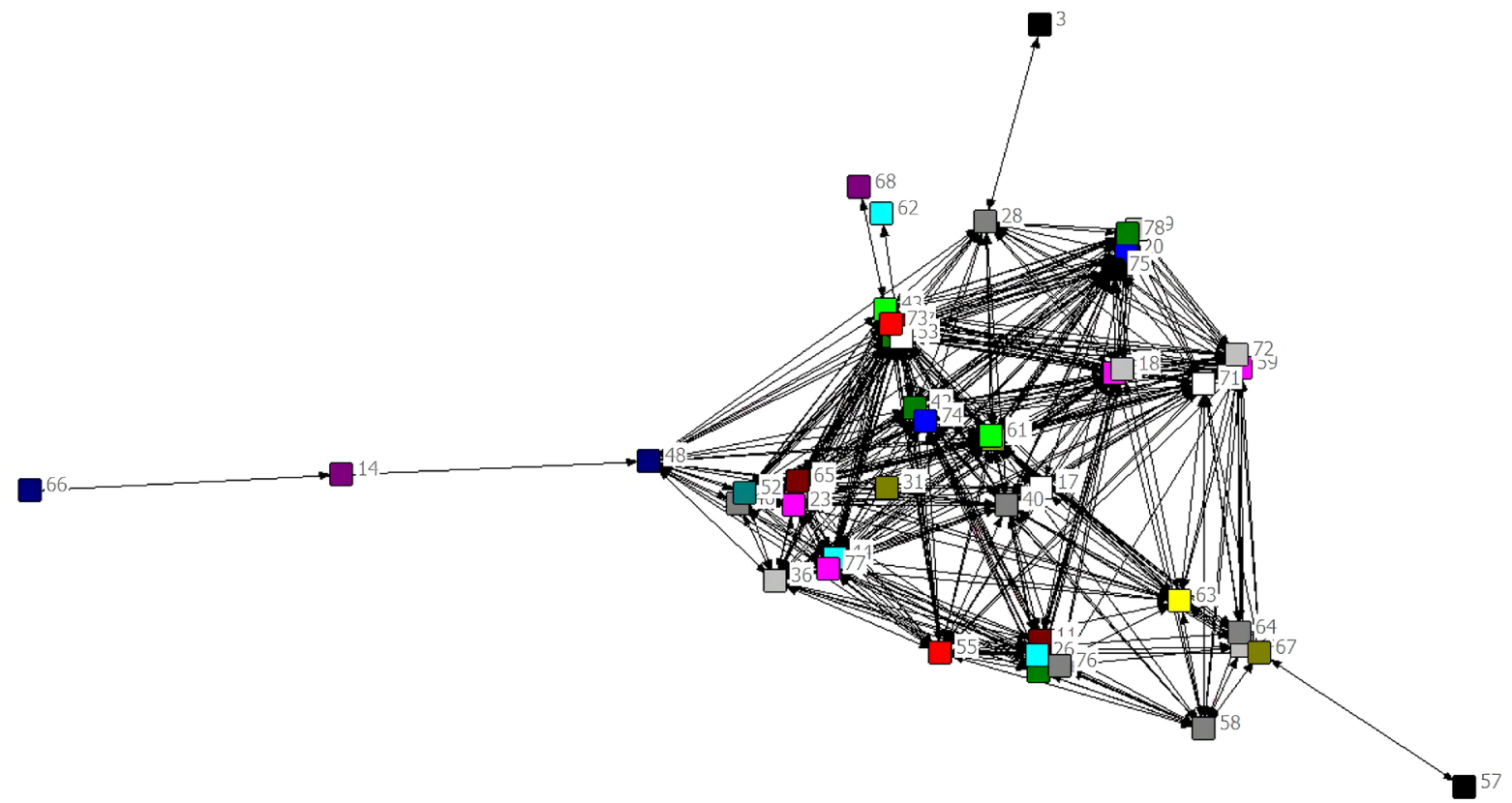

Figure 3. Network topology diagram of stock related network. 
Table 1. Some of the top shareholders with shareholding $h_{j}$ in the stock-shareholder associated network.

\begin{tabular}{|c|c|c|}
\hline Rank & Shareholders $h_{j}$ & Shareholder company $y_{j}$ \\
\hline 1 & 45 & Hong Kong Securities Clearing Company Limited \\
\hline 2 & 39 & China Securities Finance Corporation Limited \\
\hline 3 & 27 & Central Huijin Asset Management Co., Ltd. \\
\hline 4 & 25 & Hong Kong Securities Clearing (Nominees) Limited \\
\hline 5 & 18 & $\begin{array}{l}\text { China Construction Bank Co., Ltd.-Cathay Pacific China } \\
\text { Securities All Index Securities Company Trading Open Index } \\
\text { Securities Investment Fund }\end{array}$ \\
\hline 6 & 7 & Central Huijin Investment Co., Ltd. \\
\hline 7 & 6 & $\begin{array}{l}\text { China Construction Bank Co., Ltd.-Huabao China Securities All } \\
\text { Index Securities Company Trading Open Index Securities } \\
\text { Investment Fund }\end{array}$ \\
\hline 8 & 4 & Shanghai Haiyan Investment Management Co., Ltd. \\
\hline 9 & 4 & China Life Insurance Co., Ltd.-Universal Insurance Products \\
\hline 10 & 4 & Yunnan Hehe (Group) Co., Ltd. \\
\hline 11 & 4 & Wutongshu Investment Platform Co., Ltd. \\
\hline 12 & 3 & Shenergy (Group) Co., Ltd. \\
\hline 13 & 3 & $\begin{array}{l}\text { Linghang Investment Australia Limited-Linghang Emerging } \\
\text { Markets Stock Index Fund (Exchange) }\end{array}$ \\
\hline 14 & 3 & $\begin{array}{l}\text { Industrial and Commercial Bank of China-SSE } 50 \text { Trading Open } \\
\text { Index Securities Investment Fund }\end{array}$ \\
\hline 15 & 3 & $\begin{array}{l}\text { Dacheng Fund-Agricultural Bank-Dacheng China Securities } \\
\text { Financial Asset Management Plan }\end{array}$ \\
\hline 16 & 3 & $\begin{array}{l}\text { China Asset Management-Agricultural Bank of China-China } \\
\text { Securities Financial Asset Management Plan }\end{array}$ \\
\hline 17 & 3 & $\begin{array}{l}\text { China Europe Fund-Agricultural Bank-China Europe and China } \\
\text { Securities Financial Asset Management Plan }\end{array}$ \\
\hline 18 & 3 & Shanghai Jiushi (Group) Co., Ltd. \\
\hline 19 & 3 & China Everbright Group Corporation \\
\hline 20 & 3 & China Construction Bank Investment Co., Ltd. \\
\hline 21 & 3 & $\begin{array}{l}\text { Yinhua Fund-Agricultural Bank-Yinhua China Securities } \\
\text { Financial Asset Management Plan }\end{array}$ \\
\hline 22 & 3 & $\begin{array}{l}\text { China Life Insurance Company Limited-Traditional- } \\
\text { General Insurance Products-005L-CT001Shanghai }\end{array}$ \\
\hline 23 & 3 & Ministry of Finance of the People's Republic of China \\
\hline
\end{tabular}

Ltd. and Hong Kong Securities Clearing (Nominees) Limited. Among them, Hong Kong Securities Clearing Co., Ltd. and Hong Kong Securities Clearing (Nominees) Co., Ltd., ranked first and fourth, are both wholly-owned subsidiaries of the Hong Kong Stock Exchange. The former represents a collection of A shares held by the Hong Kong Stock Exchange, and the latter Represents a col- 
lection of shares held by H-share shareholders. Hong Kong Securities Clearing Company Limited is a clearing institution that operates the Hong Kong Securities Clearing and Settlement System, and investors will centrally deposit the A shares they purchase in Hong Kong Securities Clearing Company Limited. The business model of Hong Kong Securities Clearing Company Limited is similar to that of Hong Kong Securities Clearing Company Limited, except that it trades $\mathrm{H}$ shares. In other words, Hong Kong and overseas investors hold and trade A shares and $\mathrm{H}$ shares through these two companies. The holdings of these two companies are very high. Among them, Hong Kong Securities Clearing Company holds more than half of the online stocks, and their status in the Internet is very important. Because these two companies are the channels for some major shareholder companies to purchase A shares and $\mathrm{H}$ shares, their buying and selling may become the vane for ordinary shareholders to buy stocks.

China Securities Finance Co., Ltd. and Central Huijin Asset Management Co., Ltd., ranked second and third, are wholly state-owned companies funded by the state. According to the authorization of the State Council, it represents the state in accordance with the law to exercise the rights and obligations of investors in key financial enterprises such as state-owned commercial banks. They have the role of regulating and stabilizing the market.

\section{Construction and Analysis of Stock Correlation Network}

\subsection{Construction of Stock Correlation Network}

In order to better display the relationship between stocks, the stock-shareholder associated network is single-mode projection of the stock direction, and the stock correlation network and its adjacency matrix $W_{X}$ are obtained. The topological structure of the stock correlation network is shown in Figure 3.

\subsection{Analysis of Stock Correlation}

\subsubsection{Weight Distribution}

According to the definition, the adjacency matrix $W_{X}$ is a weight matrix. The weight $w_{i j}$ is expressed as the number of common neighbor nodes owned by stock $x_{i}$ and stock $x_{j}$ in shareholder $Y$. The greater the weight, the more common neighbor nodes between the two stocks. More, it means that the more organizations that are optimistic about the two listed companies at the same time, the higher the degree of recognition of the stock by the organization. Table 2 shows the weights between some stock nodes in the network.

It can be seen from Table 2 that the weight distribution of the network is non-uniform. In the network, the weight between Agricultural Bank and Bank of China is 6, which means that the shareholder composition between Agricultural Bank and Bank of China is very similar. The weight of China Everbright Bank and China Everbright Securities is also 6. This is because both stocks belong to the same parent company. Moreover, China Everbright Bank and China Everbright Securities have very close ties with traditional state-owned banks, which 
Table 2. The weights of some stocks in the stock correlation network.

\begin{tabular}{|c|c|c|}
\hline Weights $g_{i j}$ & stock $X_{i}$ & Stock $x_{j}$ \\
\hline 6 & Agricultural Bank of China $\left(x_{i}=10\right)$ & Bank of China $\left(x_{j}=5\right)$ \\
\hline 6 & Everbright Securities $\left(x_{i}=40\right)$ & Everbright $\operatorname{Ban}\left(x_{j}=19\right)$ \\
\hline 5 & Construction Bank $\left(x_{i}=13\right)$ & Agricultural Bank of China $\left(x_{j}=10\right)$ \\
\hline 5 & Industrial and Commercial Bank $\left(x_{i}=15\right)$ & Agricultural Bank of China $\left(x_{j}=10\right)$ \\
\hline 5 & Everbright Bank $\left(x_{i}=19\right)$ & Agricultural Bank of China $\left(x_{j}=10\right)$ \\
\hline 5 & Everbright Bank $\left(x_{i}=19\right)$ & Construction Bank $\left(x_{j}=13\right)$ \\
\hline$\ldots$ & $\ldots$ & $\cdots$ \\
\hline 4 & China CITIC Bank $\left(x_{i}=12\right)$ & Agricultural Bank of China $\left(x_{j}=10\right)$ \\
\hline 4 & Bank of Communications $\left(x_{i}=25\right)$ & Agricultural Bank of China $\left(x_{j}=10\right)$ \\
\hline 4 & China Merchants Securities $\left(x_{i}=34\right)$ & Agricultural Bank of China $\left(x_{j}=10\right)$ \\
\hline$\cdots$ & $\ldots$ & $\ldots$ \\
\hline 3 & Construction Bank $\left(x_{i}=13\right)$ & Bank of China $\left(x_{j}=5\right)$ \\
\hline 3 & Everbright Bank $\left(x_{i}=19\right)$ & Bank of China $\left(x_{j}=5\right)$ \\
\hline 3 & Agricultural Bank of China $\left(x_{i}=10\right)$ & Industrial Bank $\left(x_{j}=6\right)$ \\
\hline$\ldots$ & $\ldots$ & $\ldots$ \\
\hline 2 & Industrial Bank $\left(x_{i}=6\right)$ & Bank of China $\left(x_{j}=5\right)$ \\
\hline 2 & China CITIC Bank $\left(x_{i}=12\right)$ & Bank of China $\left(x_{j}=5\right)$ \\
\hline$\cdots$ & $\cdots$ & $\ldots$ \\
\hline 1 & Bank of Chengdu $\left(x_{i}=2\right)$ & Changshu Bank $\left(x_{j}=1\right)$ \\
\hline 1 & Hangzhou Bank $\left(x_{i}=4\right)$ & Changshu Bank $\left(x_{j}=1\right)$ \\
\hline$\ldots$ & $\ldots$ & $\ldots$ \\
\hline
\end{tabular}

reflects that China Everbright Group is favored by many shareholders. At the same time, we can also see that traditional state-owned banks such as China Construction Bank and Industrial and Commercial Bank are also heavily weighted. Table 3 shows the equity components of some state-owned banks.

From Table 3, we find that the holding institutions of state-owned bank stocks are highly overlapped, and most holding institutions have a national nature, that is, state-owned equity, such as China Securities Finance Corporation, the Ministry of Finance of the People's Republic of China and Central Huijin Investment Limited liability company, etc. This situation exists because of the special procedures and basic national conditions there. Current equity can provide protection for the development of banks, and legal equity can enhance the ability of banks to resist risks, so that banks are not so easy to fall when they are exposed to risks. Therefore, Conventional equity structure is the foundation for internal commercial banks to govern industrial institutions. At the same time, the above-mentioned four state-owned banks have Hong Kong Securities Clearing Company Limited in their shareholding institutions, which also reflect the important scope of Hong Kong Securities Clearing Company in the network. 
Table 3. The weights of some stocks in the stock correlation network.

\begin{tabular}{|c|c|}
\hline Stock & Top ten shareholders \\
\hline Bank of China & $\begin{array}{l}\text { Central Huijin Investment Co., Ltd., Hong Kong Securities Clearing } \\
\text { (Nominees) Limited, Wutongshu Investment Platform Co., Ltd., China Life } \\
\text { Insurance Company Limited-Dividend-Individual Dividend-005L-FH002 } \\
\text { Shanghai, Hong Kong Securities Clearing Company Limited, China Life } \\
\text { Insurance Company Limited-Traditional-General Insurance } \\
\text { Product-005L-CT001 Shanghai. }\end{array}$ \\
\hline $\begin{array}{l}\text { Agricultural Bank } \\
\text { of China }\end{array}$ & $\begin{array}{l}\text { Central Huijin Investment Co., Ltd., Ministry of Finance of the People’s } \\
\text { Republic of China, Hong Kong Securities Clearing (Nominees) Limited, } \\
\text { China Securities Finance Corporation Limited, Hong Kong Securities } \\
\text { Clearing Company Limited, Central Huijin Asset Management Co., Ltd., } \\
\text { Wutongshu Investment Platform Co., Ltd., China Life Insurance Company } \\
\text { Limited-Traditional-General Insurance Products-005L-CT001 Shanghai, } \\
\text { China Life Insurance Company Limited-Dividend-Individual } \\
\text { Dividend-005L-FH002 Shanghai }\end{array}$ \\
\hline Construction Bank & $\begin{array}{l}\text { Central Huijin Investment Co., Ltd., Hong Kong Securities Clearing } \\
\text { (Nominees) Limited, China Securities Finance Corporation Limited, Hong } \\
\text { Kong Securities Clearing Company Limited, Central Huijin Asset } \\
\text { Management Co., Ltd. }\end{array}$ \\
\hline $\begin{array}{c}\text { Industrial and } \\
\text { Commercial Bank }\end{array}$ & $\begin{array}{l}\text { Central Huijin Investment Co., Ltd., Ministry of Finance of the People's } \\
\text { Republic of China, China Ping An Life Insurance Co., } \\
\text { Ltd.-Traditional-General Insurance Products, China Securities Finance } \\
\text { Corporation Limited, Central Huijin Asset Management Co., Ltd., China Life } \\
\text { Insurance Company Limited-Traditional-General Insurance } \\
\text { Products-005L-CT001Shanghai. }\end{array}$ \\
\hline
\end{tabular}

\subsubsection{Degree Distribution and Point Weight Distribution}

The degree distribution $k$ of an undirected network is defined as the probability that the degree $P(k)$ of a randomly selected node in the network is expressed as follows:

$$
P(k)=\frac{N_{k}}{N}
$$

where $N_{k}$ represents the number of nodes with degree $k$ in the network, and $N$ is the number of nodes in the network. Figure 4 is the degree distribution image of the network.

It can be seen from Figure 5 that the degree distribution image of the stock correlation network is neither a Poisson distribution nor a power-law distribution of a scale-free network, and the degree value oscillates in an interval, and its distribution is non-uniform, causing this phenomenon The original reason is that the number of network nodes (stocks) is too small, which makes it difficult for the degree distribution to show a certain statistical law.

Since the stock association network is a weighted network, the point weight distribution analysis of the nodes in the network is carried out. The point weight distribution is similar to the degree distribution of nodes, which is defined as:

$$
P(w)=\frac{N_{w}}{N}
$$

where $P(w)$ refers to the probability that a randomly selected node in the 


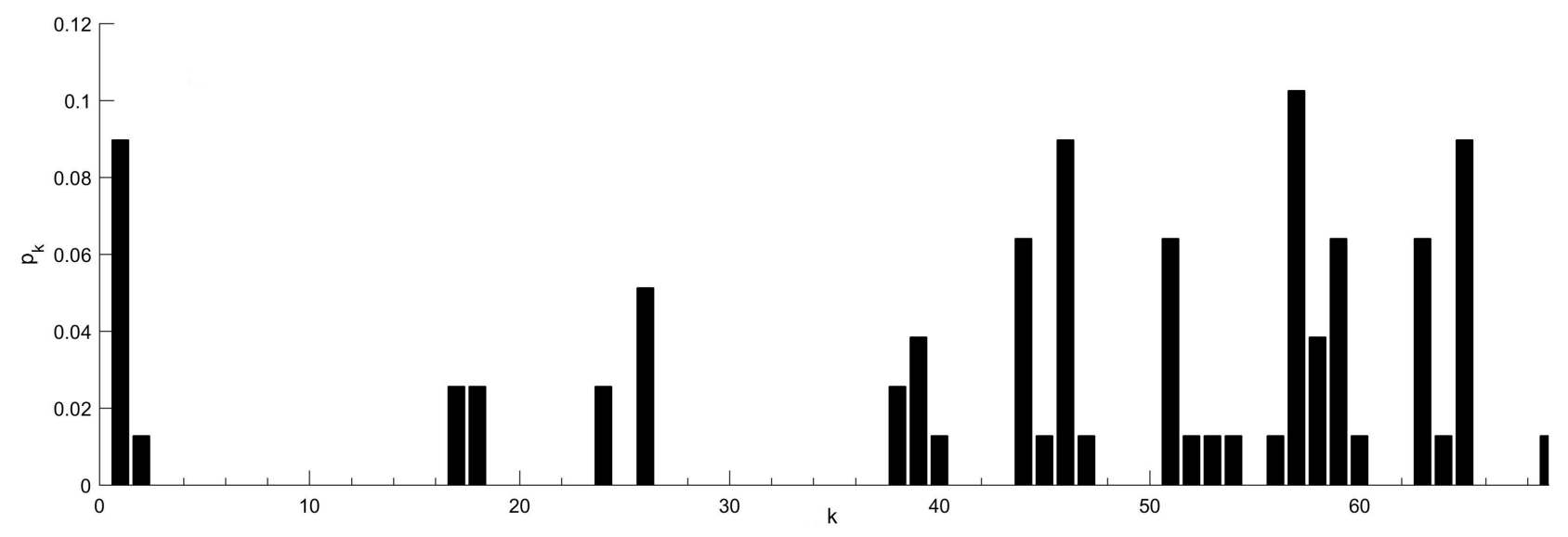

Figure 4. Degree distribution of stock related network.

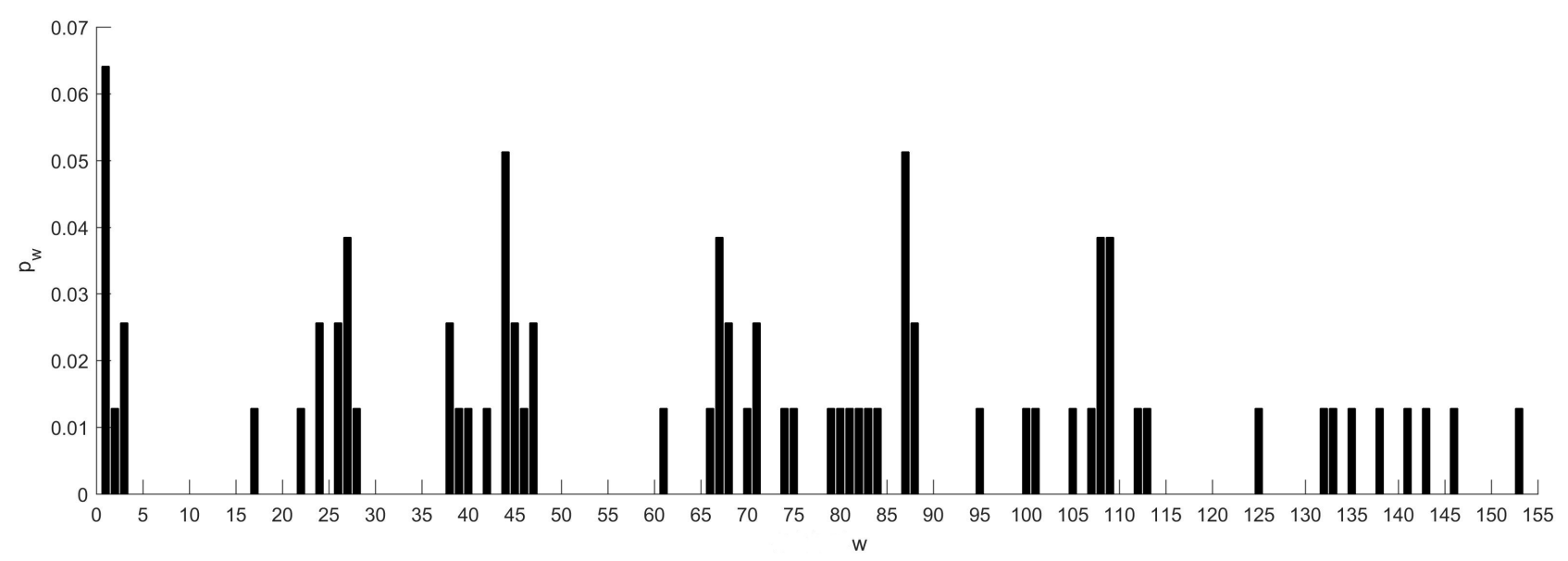

Figure 5. Point weight distribution of stock related network.

network has a weight of $w, N_{w}$ represents the number of nodes in the network with a weight of $w$, and $N$ is the number of nodes in the network. Figure 5 is the point weight distribution image of the network.

It can be seen from Figure 5 that the weights of the network nodes range from 1 to 153 . The node with a weight value of 1 has the highest appearance frequency, and most of the other nodes have the same probability of appearance, that is, they only appear once. On the whole, the point weights of most nodes in the stock-related network are concentrated between 17 - 113.

\subsubsection{Degree Centrality}

In the network, degree centrality is an indicator reflecting the importance of nodes. The greater the degree of a node, the greater its degree centrality, which means that the node is more important. In a network containing $N$ nodes, the maximum possible value of the node degree is $N-1$, and the centrality index is usually normalized for the convenience of comparison. The normalized degree centrality value of the node with degree is defined for:

$$
D C_{i}=\frac{k_{i}}{N-1}
$$


In order to more clearly extract the important information of various stocks, the original stocks are divided into three categories, namely, banking, brokerage and insurance. Tables 4-6 show the degree centrality of the three types of stocks.

It can be seen from Table 4 that among bank stocks, China CITIC Bank, China Construction Bank, Agricultural Bank, and China Everbright Bank rank

Table 4. Bank stock degree centrality.

\begin{tabular}{cccc}
\hline Stock $X_{i}$ & Stock name & Degree $k_{i}$ & $D C_{i}$ (Hundred differentiation) \\
\hline 12 & China CITIC Bank & 65 & 84.416 \\
13 & Construction Bank & 65 & 84.416 \\
10 & Agricultural Bank of China & 65 & 84.416 \\
19 & Everbright Bank & 65 & 84.416 \\
27 & China Merchants Bank & 63 & 81.818 \\
7 & Bank of Nanjing & 59 & 76.623 \\
16 & Ping An Bank & 59 & 76.623 \\
8 & Bank of Beijing & 59 & 76.623 \\
6 & Industrial Bank & 58 & 75.325 \\
29 & Shanghai Pudong Development Bank & 57 & 74.026 \\
5 & Bank of China & 57 & 74.026 \\
9 & Bank of Guiyang & 57 & 74.026 \\
18 & Chongqing Rural Commercial & 56 & 72.727 \\
$\ldots$ & $\ldots$ & $\ldots$ & $\ldots$ \\
\hline
\end{tabular}

Table 5. Brokerage stocks degree centrality.

\begin{tabular}{cccc}
\hline Stock $x_{i}$ & Stock name & Degree $k_{i}$ & $D C_{i}$ (Hundred differentiation) \\
\hline 40 & Everbright Securities & 69 & 89.610 \\
34 & China Merchants Securities & 65 & 84.416 \\
37 & GF Securities & 65 & 84.416 \\
49 & Northeast Securities & 64 & 83.117 \\
61 & Pacific Securities & 63 & 81.818 \\
42 & Huatai Securities & 63 & 81.818 \\
35 & CITIC Securities & 63 & 81.818 \\
39 & Dongxing Securities & 63 & 81.818 \\
47 & Guoyuan Securities & 60 & 77.922 \\
53 & Founder Securities & 59 & 76.626 \\
50 & Industrial Securities & 59 & 76.623 \\
55 & China Galaxy & 58 & 75.325 \\
43 & Guotai Junan & 58 & 75.325 \\
$\ldots$ & $\ldots$ & $\ldots$ & $\ldots$ \\
\hline
\end{tabular}


Table 6. Insurance stocks degree centrality.

\begin{tabular}{cccc}
\hline Stock $x_{i}$ & Stock name & Degree $k_{i}$ & $D C_{i}$ (Hundred differentiation) \\
\hline 74 & China Pacific Insurance & 65 & 84.416 \\
73 & China Life Insurance & 57 & 74.026 \\
77 & Ping An of China & 53 & 68.831 \\
75 & Xinhua Insurance & 51 & 66.234 \\
78 & Tianmao Group & 45 & 58.442 \\
76 & China People's Insurance & 26 & 33.776 \\
\hline
\end{tabular}

first in degree centrality, and the degree of the four stocks is as high as 65, reflecting the fact that these four stocks and most stocks in the network all of them are connected, occupy an important position in the network, and can reflect the overall market situation of such stocks.

It can be seen from Table 5 that among the securities stocks, Everbright Securities ranks first, China Merchants Securities and Guangfa Securities rank second, and Northeast Securities ranks third. Similarly, these four stocks also play an important role in securities stocks. At the same time, we compare Table 4 and find that the securities and banking stocks under China Everbright Group and China Merchants Bank play an important role in these two types of stocks, and their trading behavior and their own risks will have a greater impact on the network. Therefore, it is recommended that relevant departments focus on supervising the operating conditions of these two companies to prevent financial risks.

Table 6 shows the degree centrality of all insurance stocks. There are 6 insurance stocks in total. China Pacific Insurance ranks first with a degree value of 65 . It has an extremely important position in this category of stocks. China ranks second and third. Life and Ping An of China, while the lower-ranked Xinhua Insurance and Tianmao Group are relatively less central. There are two reasons for this phenomenon. On the one hand, the top three insurance stocks are all state-owned enterprises. The group was established early, with strong funds, enjoying policy dividends and occupying a large market share; on the other hand, state-owned enterprises applied for Fund loans and bank credit are easier than private companies.

Through the above analysis, we have obtained some important nodes in the stock correlation network. These nodes are in an important position in the network and will have a greater impact on the stock-related network than ordinary stocks. The relevant departments need to supervise and manage them. At the same time, when ordinary shareholders buy stocks, the market conditions of these stocks have great reference value.

\subsection{4. $K$-Core}

The $k$-core of a graph refers to repeatedly removing nodes with a degree value less than $k$ and the remaining subgraphs after connecting them [10]. The num- 
ber of nodes in the subgraph is the size of the core. If a node exists in $k$-core and is removed from $(k+1)$-core, then the number of cores of this node is $k$. In the network, the size of a node's $k$-core reflects the strength of the node's propagation ability in the network. The $k$-core of a node can be expressed as the risk spreading ability of the stock in the stock-related network. The larger the $k$-core value, the greater the risk spreading ability, and vice versa. Table 7 shows the $k$-core value of each node in the stock correlation network.

Table 7. The k-core value of each node of the stock association network.

\begin{tabular}{|c|c|}
\hline$k$-core & Stock $x_{i}$ \\
\hline 44 & $\begin{array}{l}\text { Bank of Changshu, Bank of Chengdu, Bank of Hangzhou, Bank of China, Industrial } \\
\text { Bank, Bank of Nanjing, Bank of Beijing, Bank of Guiyang, Agricultural Bank, China } \\
\text { CITIC Bank, Construction Bank, Ping An Bank, Chongqing Rural Commercial, China } \\
\text { Everbright Bank, Bank of Shanghai, Bank of Ningbo, China Merchants Bank, Bank of } \\
\text { Jiangsu, Shanghai Pudong Development Bank, China Merchants Securities, CITIC } \\
\text { Securities, GF Securities, Western Securities, Dongxing Securities, Everbright Securities, } \\
\text { Huatai Securities, Guotai Junan, Oriental Fortune, Guoyuan Securities, Northeast } \\
\text { Securities, Industrial Securities, Guosen Securities, Founder Securities, Zheshang } \\
\text { Securities, Hongta Securities, Caitong Securities, Pacific Securities, West China } \\
\text { Securities, First Ventures, Shanxi Securities, Jinlong Stocks, China Life, China Pacific } \\
\text { Insurance, Xinhua Insurance }\end{array}$ \\
\hline 38 & $\begin{array}{l}\text { Hua Xia Bank, Bank of Communications, Orient Securities, Haitong Securities, China } \\
\text { Investment Capital, Shenwan Hongyuan, China Sea Securities, Soochow Securities, } \\
\text { Yangtze River Securities, China Galaxy, Southwest Securities, Ping An }\end{array}$ \\
\hline 26 & Bank of Qingdao \\
\hline 24 & $\begin{array}{l}\text { Postal Savings Bank, Zhengzhou bank, Minsheng Bank, China Zheshang Bank, China } \\
\text { People's Insurance }\end{array}$ \\
\hline 17 & China Securities, Nanjing Securities, Huaxin shares, Hualin Securities \\
\hline 1 & $\begin{array}{l}\text { Bank of Wuxi, Zhangjiagang Bank, South China Futures, Ruida Futures, Bank of China } \\
\text { Securities, Huaan Securities, Huachuang Yangan, Great Wall Securities }\end{array}$ \\
\hline
\end{tabular}

Table 7 shows that the entire network can be divided into 6 layers, the outermost layer has a $k$-core value of 1 , and there are 7 stocks in this layer. They are at the edge of the network and have the weakest risk spreading ability. The impact is minimal. The innermost layer has a $k$-core value of 44 and contains 45 stocks, far more than half of the stocks. In this core area, from the perspective of degrees alone, comparing Table 4, it is found that there are obvious differences in the degree of core nodes. For example, some nodes with small degrees have high $k$-cores. At nodes in this core area, they have strong risk spreading capabilities. Once risks occur, they will quickly spread to the entire network. Therefore, it is recommended that relevant regulatory authorities need to focus on supervision and management of the above-mentioned stocks.

\section{Conclusions and Inspiration}

This paper studies the equity and shareholder data of financial listed companies 
in China's A-share market. From the perspective of equity holdings, the dichotomous network model is used to establish a stock-shareholder associated network, and the stock correlation network is further established through single-mode projection, reflecting the longer stable relationship between listed companies in the time period. The analysis of shareholders in the stock-shareholder associated network found that the number of shares held by some holding companies is huge, among which the number of shares held by Hong Kong Securities Clearing Company Limited, China Securities Finance Co., Ltd. and Central Huijin Asset Management Co., Ltd. ranks in the first three, Hong Kong Securities Clearing Co., Ltd. is a channel for overseas investors to purchase domestic stocks, and has a certain role as a weather vane for retail investors, while China Securities Finance and Central Huijin are state-owned enterprises with national backgrounds. The main responsibility of China Securities Finance Corporation and Central Huijin is to stabilize the market. Research on the stock-related network found that for traditional state-owned banks, the equity components between them are similar and they are closely related. This situation exists because of my country's special system and basic national conditions. State-owned equity can provide protection for the development of banks. State-owned equity can enhance the ability of banks to resist risks and make banks less likely to fall when encountering risks. Therefore, the state-owned equity holding structure is the foundation for my country's commercial banks to govern industrial institutions. The next study on the degree distribution of the stock related network found that the stock related network is not a general rule network, which is inconsistent with the traditionally believed stock network to be scale-free, and its degree distribution is non-uniform. Through the research on the centrality of the network degree, the important nodes in the stock association network are discovered. In addition, k-core analysis is performed on the network, which characterizes the risk spread ability of each node in the stock-related network. The number of nodes in the core area of the network is 45 , and the k-core value is as high as 44 . This result shows that this is a network with strong risk spreading ability. Therefore, relevant departments should supervise the listed companies in the core area of the network to prevent financial risks occur.

This paper introduces the bipartite network model into the construction of the financial stock network. Compared with the traditional threshold method, network modeling of stocks from the perspective of equity holding can study the stable relationship between stocks and shareholders over a longer period of time, and can analyze the structure and financial nature of the network through a variety of indicators. It provides new ideas for the application of complex networks in finance. It also has a certain guiding significance for investors to choose stocks, and it also provides a certain reference for financial supervision departments. At the same time, there are still some problems that have not been solved in this paper, such as single-mode projection will lose part of the information in the bipartite network, only the static network structure has been studied, and the 
dynamic network has not been further studied. I hope to continue to deepen the research in these aspects in the future.

\section{Acknowledgements}

This project was supported by the Natural Science Foundation of Guangxi (No. 2018GXNSFAA138095) and the National Natural Science Foundation of China (No. 61563013).

\section{Conflicts of Interest}

The authors declare no conflicts of interest regarding the publication of this paper.

\section{References}

[1] Lin, Y. and Chen, Z.X. (2018) Financial Network Risk Contagion Assessment Model Based on Complex Network Theory. Southern Finance, No. 5, 16-26.

[2] Sun, Y.F. and Wang, C.Y. (2018) A Financial Complex Network Model Based on Textual Mutual Information. Acta Physica Sinica, 67, 270-280. https://doi.org/10.7498/aps.67.20172490

[3] Wang, Y., Xiao, X.R., Liu, J. and Liu, L. (2019) A Review of Financial Network Structure and Risk Contagion Theory. Financial Supervision Research, No. 2, 79-96.

[4] Mi, C.M. and Qian, Y.Y. (2019) Research on Internet Financial Risk Contagion Based on SEIS Model. Journal of Nanjing University of Science and Technology, 43, 800-806.

[5] Xu, R.J., Mi, C.M., Mierzwiak, R. and Meng, R.Y. (2020) Complex Network Construction of Internet Finance Risk. Physical A: Statistical Mechanics and Its Applications, 540, Article ID: 122930. https://doi.org/10.1016/j.physa.2019.122930

[6] Hao, G.Y. and Guo, L.X. (2020) Financial Market Structure Evolution and Risk Contagion from the Perspective of Complex Networks. Financial Development Research, No. 1, 30-39.

[7] Lu, S., Wang, H.W. and Jie, G. (2019) Research on Inter-Bank Risk Contagion Based on the Bank-Asset Dichotomy Network. Mathematics in Practice and Understanding, 49, 71-80.

[8] Gu, K., Fan, Y. and Di, Z.R. (2020) How to Predict Recommendation Lists That Users Do Not Like. Physica A: Statistical Mechanics and Its Applications, 537, Article ID: 122684. https://doi.org/10.1016/j.physa.2019.122684

[9] Chen, L., Peng, J., Rao, C.J. and Rosyida, I. (2018) Cycle Index of Uncertain Random Graph. Journal of Intelligent \&Fuzzy Systems, 34. https://doi.org/10.3233/JIFS-17373

[10] Wang, X.F., Li, X. and Chen, G.R. (2006) Complex Network Theory and Its Application. Tsinghua University Press, Beijing. 